\title{
Fitness, fatness, and coronary heart disease risk in adolescents: the Northern Ireland Young Hearts Project
}

Boreham, C., Twisk, J., Murray, L., Savage, M., Strain, J. J., \& Cran, G. (2001). Fitness, fatness, and coronary heart disease risk in adolescents: the Northern Ireland Young Hearts Project. Medicine \& Science in Sports \& Exercise, 33(2), 270-274.

\section{Published in:}

Medicine \& Science in Sports \& Exercise

Queen's University Belfast - Research Portal:

Link to publication record in Queen's University Belfast Research Portal

\section{General rights}

Copyright for the publications made accessible via the Queen's University Belfast Research Portal is retained by the author(s) and / or other copyright owners and it is a condition of accessing these publications that users recognise and abide by the legal requirements associated with these rights.

Take down policy

The Research Portal is Queen's institutional repository that provides access to Queen's research output. Every effort has been made to ensure that content in the Research Portal does not infringe any person's rights, or applicable UK laws. If you discover content in the Research Portal that you believe breaches copyright or violates any law, please contact openaccess@qub.ac.uk. 


\title{
Fitness, fatness, and coronary heart disease risk in adolescents: the Northern Ireland Young Hearts Project
}

\author{
COLIN BOREHAM, JOS TWISK, LIAM MURRAY, MAURICE SAVAGE, J. J. STRAIN, and GORDON CRAN
}

University of Ulster, UNITED KINGDOM; Vrije Universiteit, Amsterdam, THE NETHERLANDS; and The Queen's University of Belfast, UNITED KINGDOM

\begin{abstract}
BOREHAM, C., J. TWISK, L. MURRAY, M. SAVAGE, J. J. STRAIN, and G. CRAN. Fitness, fatness, and coronary heart disease risk in adolescents: the Northern Ireland Young Hearts Project. Med. Sci. Sports Exerc., Vol. 33, No. 2, pp. 270-274, 2001. Purpose: The purpose of this study was to examine the independence and relative strengths of association between coronary heart disease (CHD) risk status and both body fatness and cardiorespiratory (C-R) fitness in 12- and 15-yr-old adolescents. Methods: The study cohort consisted of 1015 schoolchildren aged 12 and 15 yr (251 12-yr-old boys, 258 12-yr-old girls, 252 15-yr-old boys, and 25415 -yr-old girls), representing a $2 \%$ random sample of each population group. For each child, height, weight, sexual maturity (pubertal status), skin-fold thicknesses (4 sites), blood pressure (random zero sphygmomanometer), nonfasting serum total, and high density lipoprotein (HDL)-cholesterol and C-R fitness (20-m shuttle run; 20-MST) were determined under standardized conditions. Socioeconomic status and habitual physical activity were also determined from questionnaire information. Multiple regression analyses were carried out to examine relationships between five CHD risk factors, and fitness and fatness and to examine the relative strengths of fitness and fatness on CHD risk status, correcting for potential confounding variables. Results: Our main findings were: 1) Relationships between fatness and CHD risk factors are invariably stronger than between fitness and the same risk factors. For example, partially adjusted standardized regression coefficients for 12-yr-old boys revealed significant relationships between all five CHD risk factors and fatness, compared with three of five for fitness. The corresponding figures for 12-yr-old girls were three of five (fatness) and one of five (fitness). Broadly similar results were apparent for 15-yr-olds. 2) Although relationships between fitness and CHD risk factors do not survive further adjustment for fatness, the relationships between fatness and CHD risk are more robust and are unaffected by further adjustment for fitness. Conclusion: Our results indicate that the observed relationships between C-R fitness and CHD risk status in adolescents are mediated by fatness, whereas the observed relationships with fatness are independent of fitness. Primary prevention of CHD during childhood should therefore concentrate upon preventing or reversing undue weight gain. Key Words: OBESITY, AEROBIC FITNESS, CARDIOVASCULAR HEALTH, YOUNG PEOPLE
\end{abstract}

I $\mathrm{n}$ adult populations, strong inverse associations have been demonstrated between aerobic fitness and both coronary heart disease (CHD) risk factor status $(16,37,45)$ and CHD mortality $(13,34)$. These relationships hold for men and for women, and are independent of other potential confounding risk factors, including body fatness. In children and adolescents, however, these relationships appear to differ. Although higher levels of fitness are consistently associated with more favorable CHD risk factor profiles in children, several studies have indicated that such relationships may be mediated by body fatness rather than aerobic fitness per se $(5,17,20,33,39)$. Because CHD is a lifelong process (4), such generational differences in the etiology of risk, if confirmed, would have major implications for risk reduction strategies employed at different stages of the life course. The purpose of the present study was to further examine the relationships between CHD risk

0195-9131/01/3302-0270/\$3.00/0

MEDICINE \& SCIENCE IN SPORTS \& EXERCISE E $_{\circledast}$

Copyright (C) 2001 by the American College of Sports Medicine

Received for publication September 1999.

Accepted for publication May 2000. status and both fatness and fitness in 12- and 15-yr old adolescents, and to establish the relative independence and strengths of association so that appropriate CHD preventive strategies can be formulated for this age group.

\section{MATERIALS AND METHODS}

The Young Hearts Project is a longitudinal study of CHD risk factors in a sample of young people from Northern Ireland. The original baseline survey, which provides the basis for the current investigation, was completed in 1990 (9).

Subjects. The study population consisted of 1015 schoolchildren (251 12-yr-old boys, 258 12-yr-old girls, 252 15-yr-old boys, and 254 15-yr-old girls) selected from 16 schools in a random, stratified sample representative of each of the five regional school boards, as well as the two sectors of postprimary education in Northern Ireland. The target sample size of 250 per age/gender group was based on the variability of pilot study results and represented a $2 \%$ random sample of each population group. A more detailed account of sampling methodology and response characteristics is given elsewhere (9). The overall response rate was 


\begin{tabular}{|c|c|c|c|c|}
\hline & \multicolumn{2}{|c|}{ Boys } & \multicolumn{2}{|c|}{ Girls } \\
\hline & $12 \mathrm{yr}(N=251)$ & 15 yr $(N=252)$ & 12 yr $(N=258)$ & 15 yr $(N=254)$ \\
\hline Height (cm) & $149.7(7.9)$ & $168.9(7.2)$ & $151.0(7.5)$ & $160.1(5.9)$ \\
\hline Weight (kg) & $42.6(9.4)$ & $58.6(9.4)$ & $44.0(9.0)$ & $56.6(8.6)$ \\
\hline Sum of four skinfolds (cm) & $37.9(20.6)$ & $34.1(16.4)$ & $43.6(15.8)$ & $52.1(16.8)$ \\
\hline 20-m shuttle run (no. of laps) & $58.7(18.8)$ & $79.2(21.3)$ & $44.3(13.2)$ & $45.4(13.6)$ \\
\hline Systolic BP (mm Hg) & $111.0(11.6)$ & $123.2(12.4)$ & $111.6(12.2)$ & $118.2(11.8)$ \\
\hline Diastolic BP (mm Hg) & $68.0(9.5)$ & $73.4(9.4)$ & $70.8(9.1)$ & $74.2(8.8)$ \\
\hline Total cholesterol $\left(\left.\mathrm{mmol} \cdot\right|^{-1}\right)$ & $4.6(0.8)$ & $4.2(0.7)$ & $4.7(0.8)$ & $4.6(0.8)$ \\
\hline $\mathrm{HDL}\left(\left.\mathrm{mmol} \cdot\right|^{-1}\right)$ & $1.4(0.3)$ & $1.3(0.3)$ & $1.4(0.3)$ & $1.4(0.3)$ \\
\hline $\mathrm{TC}: \mathrm{HDL}$ & $3.5(1.0)$ & $3.5(1.0)$ & $3.6(0.9)$ & $3.5(0.8)$ \\
\hline $\begin{array}{l}\text { Correlation between fitness } \\
\text { and fatness }\end{array}$ & -0.62 & -0.46 & -0.50 & -0.41 \\
\hline
\end{tabular}

$78 \%$ with no discernible pattern for nonparticipation that would influence the validity of the random nature of the sample. Ethical approval was obtained from the Medical Research Ethical Committee of The Queen's University of Belfast, and written consent was obtained from the parent or guardian and all participating children.

Testing procedures. For each child the test protocol included a medical examination during which height, weight, and sexual maturity by pubertal status (38) were determined. Skin-fold thicknesses were obtained from four sites (biceps, triceps, subscapular, and suprailiac) and summed for the estimation of body fatness (44). Blood pressure was measured twice from the right arm, using a Hawksley random-zero sphygmomanometer, with subjects sitting quietly beforehand for at least $5 \mathrm{~min}$. Systolic blood pressure (SBP) was recorded as the mean of the two values for Korotkoff phase I, whereas the diastolic blood pressure (DBP) was based on the mean of two values for phase $\mathrm{V}$ (15-yr-olds) or phase IV (12-yr-olds). Nonfasting blood samples were drawn from the antecubital vein under local anesthesia and separated into serum/plasma within $4 \mathrm{~h}$. Total cholesterol concentration was estimated by an enzymatic technique (CHOD-PAP, Boehringer Mannheim, Mannheim, Germany) and HDL cholesterol concentration by phosphotungstic magnesium reagents. All assays were performed in a laboratory conforming to World Health Organization standards. During the period of the study, intra-assay coefficients of variation (C-vs) were $<3.0 \%$ for total and HDL cholesterol measurements, and inter assay $\mathrm{C}$-vs were $<5.0 \%$. Socioeconomic status was determined from occupational information provided by the parent or guardian of each child and was classified according to the Office of Population Census and Surveys (28). A physical activity score was computed for each subject based on confidential questionnaire information on everyday physical activities (for example, method of transportation to and from school, activities during breaks in the school day, sports participation after school, and so on). Children were "cued" with a time-based framework using the structure of a typical school day. This method was felt to be more appropriate than cueing by activities, which is the more traditional method (3). Answers were coded according to frequency, intensity, and duration, appropriately weighted, and the activity score (from 1 to 100) computed (30). Although spe- cific psychometric data are not available for this questionnaire, it has demonstrated both concurrent validity (25) and predictive validity in relation to physical fitness (10). Cardiorespiratory fitness (C-R fitness) was determined by the $20-\mathrm{m}$ endurance shuttle run. This test requires subjects to run back and forth between two lines set $20 \mathrm{~m}$ apart. Running pace is determined by audio signals, emitted from a prerecorded cassette tape, the initial velocity being 8.5 $\mathrm{km} \cdot \mathrm{h}^{-1}$, and increasing by $0.5 \mathrm{~km} \cdot \mathrm{h}^{-1}$ every minute. A constant level of encouragement is given to participants throughout the test. The test is terminated when the child fails to reach the end lines concurrent with the audio signals on two consecutive occasions. Scoring is by "laps" completed, and the test has been validated for use with children $(11,43)$. Throughout the duration of the project, all tests were carried out in the same order by the same members of the testing team.

Statistical analyses. Data were coded, checked, and entered onto an ICL 3980 mainframe computer for subsequent analysis using SPSSX. To assess the relationship between fitness and fatness, Pearson product moment correlation coefficients were calculated between these two parameters for all four age and gender groups. To examine the relationship between CHD risk status and fitness and fatness and to examine the relative importance of fitness and fatness, several multiple regression analyses were carried out. First, a "crude" analysis was performed in which fitness and fatness were related to CHD risk factors separately, correcting for social class and maturation. Second, multiple linear regression analyses were carried out in which both fitness and fatness were analyzed together in relation to CHD risk factors, again correcting for social class and maturation; the second analysis will be referred to as "adjusted" analysis. Both crude and adjusted analysis were performed for all four age and gender groups.

\section{RESULTS}

Table 1 shows the descriptive data for the main variables measured at age 12 and $15 \mathrm{yr}$, and the Pearson's product moment correlations between aerobic fitness and fatness for all four age/sex groups. The correlation coefficients indicate moderate to strong relationships for all groups. 


\begin{tabular}{|c|c|c|c|c|c|c|c|c|}
\hline & \multicolumn{4}{|c|}{ Boys (12 yr) } & \multicolumn{4}{|c|}{ Boys (15 yr) } \\
\hline & \multicolumn{2}{|c|}{ Fitness } & \multicolumn{2}{|c|}{ Fatness } & \multicolumn{2}{|c|}{ Fitness } & \multicolumn{2}{|c|}{ Fatness } \\
\hline & Crude & Adjusted & Crude & Adjusted & Crude & Adjusted & Crude & Adjusted \\
\hline Systolic BP & $-0.16^{\star}$ & 0.01 & $0.29^{* *}$ & $0.27^{\star *}$ & -0.04 & 0.03 & $0.13^{*}$ & $0.14^{*}$ \\
\hline Diastolic BP & -0.11 & 0.11 & $0.30^{* *}$ & $0.35^{\star \star}$ & 0.01 & 0.09 & $0.17^{\star}$ & $0.21^{* *}$ \\
\hline Total cholesterol & $-0.28^{\star \star}$ & -0.11 & $0.36^{\star *}$ & $0.27^{\star \star}$ & $-0.19^{*}$ & -0.10 & $0.23^{\star *}$ & $0.19 * *$ \\
\hline HDL cholesterol & 0.06 & -0.05 & $-0.13^{\star}$ & $-0.17^{\star}$ & $0.14^{\star}$ & 0.09 & $-0.14^{\star}$ & -0.10 \\
\hline TC:HDL & $-0.22^{\star *}$ & -0.04 & $0.31^{* *}$ & $0.29^{\star *}$ & $-0.21^{\star *}$ & -0.13 & $0.24^{\star *}$ & $0.18^{*}$ \\
\hline
\end{tabular}

Crude, correcting for social class and maturation; Adjusted, also correcting for either fitness (20-m shuttle run score) or fatness (sum of four skinfolds).

${ }^{\star} P<0.05 ;{ }^{* \star} P<0.01$.

Tables 2 and 3 show the standardized regression coefficients for relationships between aerobic fitness, fatness, and $\mathrm{CHD}$ risk factors for boys and girls, respectively. The tables are arranged so that regression coefficients can be compared between crude analyses (whereby statistical correction is made for social class and maturation) and adjusted analyses, which includes additional adjustment for fitness (if the independent variable is fatness) or fatness (if the independent variable is fitness). Such an arrangement allows a judgement on the relative importance of fitness and fatness, regarding their relationship with CHD risk factors.

It is clear from both Tables 2 and 3 that, first, relationships (crude) between fatness and CHD risk factors are invariably stronger than between fitness and the same risk factors. Second, although the relationships between fitness and CHD risk factors do not, in the main, survive further adjustment for fatness, the relationships between fatness and CHD risk factors are more robust and are unaffected by further adjustment for fitness. Thus, the relationship observed for fitness in the crude analyses can be explained by the association with fatness, whereas the observed relationships with fatness are independent of fitness. Finally, in general, the above relationships are stronger for male rather than female subjects, and for younger rather than older adolescents.

\section{DISCUSSION}

In keeping with previous studies in children, the present investigation revealed moderate to strong correlations between fitness and fatness $(17,20,39)$ and between fitness and CHD risk factors $(5,33,39)$. However, the latter were strongly confounded by body fatness, whereas the more robust associations found between fatness and CHD risk factors proved to be independent of fitness and other potential confounders. Although such results may be partly in- fluenced by the more objective nature of the fatness test compared with the C-R fitness test employed in the present study, the overall findings confirm that children's health status may be influenced more by body fatness than by aerobic fitness. This is in contrast to the reported findings from adult studies, which have, on the whole, shown that fitness and changes in fitness are strong predictors of CHD risk and mortality, which are largely independent of body fatness $(7,8,13,16,34,37,45)$. At least part of the explanation for this discrepancy may lie in the different end points used by children's and adult studies. Although the latter have recourse to CHD mortality as a dependent variable, studies on children are restricted to levels of precursor risk factors for atherosclerosis. Thus, different independent relationships may exist between fitness and CHD mortality in adults, and fatness and CHD risk status in children. It is known, for example, that higher levels of physical activity and fitness in adults may protect against acute cardiac events by a variety of mechanisms including a reduced myocardial vulnerability to ventricular arrhythmias, reduced platelet stickiness and aggregability, and increased fibrinolysis $(21,24)$. Acute coronary events are extremely rare in children, however, and so this protective mechanism of physical activity and fitness is not manifest (or is of little relevance). Rather, factors affecting precursors of atherosclerosis are of paramount importance, because atherosclerosis is now established as a lifelong degenerative process (4) beginning in childhood. In this regard, our study, in keeping with others $(5,17,18,20,33,39)$ indicates that high fatness rather than low fitness is related independently to poorer CHD risk factors status in children.

Childhood obesity has been strongly implicated in the clustering of risk factors $(2,6,18,36,41)$ and their tracking into young adulthood $(2,14,42)$. Pathological evidence has also linked antemortem levels of fatness in children with the extent of atherosclerosis in major arteries at autopsy $(4,23)$,

TABLE 3. Standardized regression coefficients regarding the relationship between fitness, fatness, and CHD risk factors for girls.

\begin{tabular}{|c|c|c|c|c|c|c|c|c|}
\hline & \multicolumn{4}{|c|}{ Girls (12 yr) } & \multicolumn{4}{|c|}{ Girls (15 yr) } \\
\hline & \multicolumn{2}{|c|}{ Fitness } & \multicolumn{2}{|c|}{ Fatness } & \multicolumn{2}{|c|}{ Fitness } & \multicolumn{2}{|c|}{ Fatness } \\
\hline & Crude & Adjusted & Crude & Adjusted & Crude & Adjusted & Crude & Adjusted \\
\hline Systolic BP & 0.01 & 0.11 & $0.12^{*}$ & $0.18^{\star}$ & $-0.19^{\star \star}$ & -0.09 & $0.27^{\star *}$ & $0.22^{* \star}$ \\
\hline Total cholesterol & 0.04 & 0.12 & 0.11 & $0.17^{\star}$ & -0.02 & 0.04 & $0.13^{*}$ & $0.14^{\star}$ \\
\hline HDL cholesterol & $0.16^{\star}$ & 0.08 & $-0.22^{\star \star}$ & $-0.18^{*}$ & 0.05 & -0.04 & $-0.20^{* *}$ & $-0.22^{\star * *}$ \\
\hline TC:HDL & -0.11 & 0.03 & $0.26^{\star *}$ & $0.27^{\star \star}$ & -0.05 & 0.07 & $0.27^{\star \star}$ & $0.30^{* *}$ \\
\hline
\end{tabular}

Crude, correcting for social class and maturation; Adjusted, also correcting for either fitness (20-m shuttle run score) or fatness (sum of four skinfolds).

${ }^{\star} P<0.05 ;{ }^{\star *} P<0.01$. 
whereas a longer-term study (27) has shown that overweight in adolescence was a more powerful predictor of adult morbidity and mortality than overweight in adulthood. It would also appear that relationships between fatness and CHD risk status are somewhat stronger than those previously reported between physical activity and CHD status for this population (10).

Such evidence suggests that childhood obesity may well be the single most important modifiable risk factor in the pathogenesis of CHD during childhood. What are the implications of such findings for public health and primary prevention strategies? It is clear that an emphasis on improving physical fitness levels in middle-aged men and women as a strategy for the prevention of CHD is justified based on the available evidence from adult studies $(8,13,34)$. Evidence for the benefits of weight loss for cardiovascular health in adults is more equivocal. Indeed, advocating weight loss in middle-aged individuals may even increase the risk of CHD (15). However, for children there appears to be a prima facia case for the primary focus on prevention of CHD to be on the avoidance or reversal of undue weight gain. Prevention is of particular importance, because it is estimated that $80 \%$ of obese adolescents become obese adults (33). More worryingly, despite the acknowledged adverse health outcomes associated with childhood obesity and despite increasing obesity among the pediatric popula-

\section{REFERENCES}

1. Andersen, R. E., C. J. Crespo, S. J. Bartlett, L. J. Cheskin, and M. PratT. Relationship of physical activity and television watching with body weight and level of fatness among children. JAMA 279:938-942, 1998.

2. Bao, W., S. R. Srinivasan, W. A. Wattigney, and G. S. Berenson. Persistence of multiple cardiovascular risk clustering related to Syndrome X from childhood to young adulthood. Arch. Intern. Med. 154:1842-1847, 1994.

3. BARANOWSKI, T. Validity and reliability of self-report measures of physical activity: an information processing perspective. Res. $Q$. 59:314-327, 1988.

4. Berenson, G. S., S. R. Srinivasan, W. Bao, W. P. Newman, R. E. Tracy, and W. A. Wattigney. Association between multiple cardiovascular risk factors and atherosclerosis in children and young adults. N. Engl. J. Med. 338:1650-1656, 1998.

5. Bergström, E., O. Hernell, and Å. Persson. Endurance running performance in relation to cardiovascular risk indicators in adolescents. Int. J. Sports Med. 18:300-307, 1997.

6. Bergström, E., O. Hernell, L. A. Persson, and B. Vessby. Insulin Resistance Syndrome in Adolescents. Metabolism 45:908-914, 1996.

7. Blair, S. N., J. B. Kampert, H. W. Kohl III, et al. Influence of cardiorespiratory fitness and other precursors on cardiovascular disease and all-cause mortality in men and women. JAMA 276: 205-210, 1996.

8. Blair, S. N., H. W. Kohl III, C. E. Barlow, R. S., Paffenbarger, L. W. GibBons, and C. A. Macera. Changes in physical fitness and all cause mortality: a prospective study of healthy and unhealthy men. JAMA 273:1093-1098, 1995.

9. Boreham, C., Savage, J. M. Primrose, et al. Coronary risk factors in schoolchildren. Arch. Dis. Child. 68:182-186, 1993.

10. Boreham, C. A., J. Twisk, M. J. Savage, G. W. Cran, and J. J. STRAIN. Physical activity, sports participation, and risk factors in adolescents. Med. Sci. Sports Exerc. 29:788-793, 1997.

11. Boreham, C., V. J. Paliczka, and A. K. Nichols. A comparison of the PWC170 and 20-MST tests of aerobic fitness in adolescent schoolchildren. J. Sports Med. Phys. Fitness 30:19-23, 1990. tions of developed countries (40), it is estimated that only $20 \%$ of obese adolescents receive treatment for their condition. The cornerstones of such preventive measures on a population basis are enhanced physical activity levels $(10,26,29)$ and adoption of a healthier diet (32). Indeed, an earlier analysis of this population (10) indicated that for adolescent females at least, there is an inverse relationship between physical activity levels and percentage body fat. As physical activity is a behavior, whereas physical fitness is an attribute (31), behavioral intervention at a young age is required. Specific measures relating to a reduction of television viewing time $(1,12)$, increased exercise (19), and healthier school meals (22) may prove particularly effective.

In conclusion, the results of the present-day study confirm previous reports that fatness is strongly and independently associated with CHD risk status in adolescents and that aerobic fitness is not. Primary prevention of CHD during childhood should therefore concentrate upon preventing or reversing undue weight gain.

Funding sources: This work was supported by grants from the British Heart Foundation, The Wellcome Trust, and the Northern Ireland Chest, Heart, and Stroke Association.

Address for correspondence: Colin Boreham, Professor of Sport and Exercise Science Sports Studies, Faculty of Business and Management, University of Ulster at Jordanstown, Shore Road, Newtownabbey Co., Antrim BT37 OQB, United Kingdom; E-mail: ca.boreham@ulst.ac.uk.

12. Epstein, L. H., A. M. Valoski, L. S. Vara, et al. Effects of decreasing sedentary behaviour and increasing activity on weight change in obese children. Health Psychol. 14:109-115, 1995.

13. Farrell, S. W., J. B. Kampert, H. W. Kohl III, et al. Influences of cardiorespiratory fitness levels and other predictors on cardiovascular disease mortality in men. Med. Sci. Sports Exerc. 30: 899-905, 1998

14. Freedman, D. S., G. L. Burke, D. W. Harsha, et al. Relationship of changes in obesity to serum lipid and lipoprotein changes in childhood and adolescence. JAMA 254:515-520, 1985.

15. Galanis, D. J., T. Harris, D. S. Sharp, and H. Petrovitch. Relative weight, weight change and risk of CHD in the Honolulu Heart Program. Am. J. Epidemiol. 147:379-86, 1998.

16. Gibbons, L. W., S. N. Blair, K. H. Cooper, and M. H. Smith. Associations between coronary heart disease risk factors and physical fitness in healthy, adult women. Circulation 67:977-983, 1983.

17. Gutin, B., S. Islam, T. Mamos, N. Cucuzzo, C. Smith, and M. STACHURA. Relation of percentage of body fat and maximal aerobic capacity to risk factors for atherosclerosis and diabetes in black and white seven-to eleven-year-old children. J. Pediatr. 125:847$852,1994$.

18. Gutin, B., S. Owens, F. Treiber, S. Islam, W. Karp, and G. SLAVENs. Weight-independent cardiovascular fitness and coronary risk factors. Arch. Pediatr. Adolesc. Med. 151:462-465, 1997.

19. Gutin, B., and Owens, S. Role of exercise intervention in improving body fat distribution and risk profile in children. Am. J. Hum. Biol. 11:237-247, 1999.

20. Hager, R. L., L. A. Tucker, and G. T. SeljaAs. Aerobic fitness, blood lipids and body fat in children. Am. J. Public Health 85: 1702-1706, 1995.

21. Leon, A. S., and J. Nordstrom. Evidence of the role of physical activity and cardiorespiratory fitness in the prevention of coronary heart disease. Quest 47:311-319, 1995.

22. Luepker, R. V., C. L. Perry, S. M. Mckinlay, et al. Outcomes of a field trial to improve children's dietary patterns and physical 
activity: the Child and Adolescent Trial for Cardiovascular Health (CATCH). JAMA 275:768-776, 1996.

23. Mcgill, H. C., and C. A. Mcmahon. Determinants of atherosclerosis in the young. Pathobiological Determinants of Atherosclerosis in Youth (PDAY) Research Group. Am. J. Cardiol. 82:30T36T, 1998

24. Mittleman, M. A., M. Maclure, G. H. Tofler, J. B. Sherwood, R. J. Goldberg, and J. E. Muller, for the Determinants of Myocardial Infarction Onset Study Investigators. Triggering of acute myocardial infarction by heavy physical exertion: protection against triggering by regular exertion. N. Engl. J. Med. 329:1677-1683, 1993.

25. Montoye, H. J., H. C. G Kemper, W. H. M. Saris, and R. A. Washburn. Measuring Physical Activity and Energy Expenditure. Champaign, IL: Human Kinetics, 1996, p. 57.

26. Moore, L. L., U-S. D. T. Nguyen, K. J. Rothman, L. A. Cupples, and R. C. Ellison. Preschool physical activity level and change in body fatness in young children: the Framingham Children's Study. Am. J. Epidemiol. 142:982-988, 1995.

27. Must, A., P. R. Jacques, G. E. Dallal, C. J. Bajema, and W. H. DIETZ, Long-term morbidity and mortality of overweight adolescents: a follow-up of the Harvard Growth Study of 1922 to 1935. N. Engl. J. Med. 327:1350-1355, 1992.

28. Office of Population Censuses and Surveys. A publication of the Government Statistical Service Standard Occupational Classification (Vol. 1, 2, and 3) London: HMSO, 1990.

29. Raitakari, O. T., K. V. K. Porkka, S. Taimela, R. Telama, L. Rasanen, and J. S. A. ViIKari. Effects of persistent physical activity and inactivity on coronary risk factors in children and young adults: the Cardiovascular Risk in Young Finns Study. Am. J. Epidemiol. 140:195-205, 1994.

30. Riddoch, C., J. M. Savage, N. Murphy, G. Cran, and C. Boreham. Long term health implications of fitness and physical activity patterns. Arch. Dis. Child. 66:1426-1433, 1991.

31. Riddoch, C. J., and C. A. G. Boreham. The health-related physical activity of children. Sports Med. 19:86-102, 1996.

32. Sabaté, J., K. D. Lindsted, R. D. Harris, and P. K. Johnston. Anthropometric parameters of schoolchildren with different lifestyles. Am. J. Dis. Child. 144:1159-1163, 1990.

33. Sallis, J. F., T. L. Patterson, M. J. Buono, and P. R. Nader. Relation of cardiovascular fitness and physical activity to cardiovascular disease risk factors in children and adults. Am. J. Epidemiol. 127:933-941, 1988.
34. Sandvik, L., J. Erikssen, E. Thaulow, G. Erikssen, R. Mundal, and K. RoDAHL. Physical fitness as a predictor of mortality among healthy, middle-aged Norwegian men. N. Engl. J. Med. 328:533537, 1993.

35. Schonfeld-Warden, N., and C. H. Warden. Pediatric obesity: an overview of etiology and treatment. Pediatr. Clin. North Am. 44:339-361, 1997.

36. Smoak, C. G., G. L. Burke, L. S. Webber, D. W. Harsha, S. R. SRINIVASAN, and G. S. BERENSON. Relation of obesity to clustering of cardiovascular disease risk factors in children and young adults: the Bogalusa Heart Study. Am. J. Epidemiol. 125:364-372, 1987.

37. Takemura, Y., S. Kikuchi, Y. Inaba, H. J. Yasuda, and K. NAKagawa. The protective effect of good physical fitness when young on the risk of impaired glucose tolerance when old. Prev. Med. 28:14-19, 1999.

38. TAnner, J. M. Growth at Adolescence. Oxford: Blackwell, 1962.

39. Tell, G. S., and O. D. Vellar. Physical fitness, physical activity and cardiovascular disease risk factors in adolescents: the Oslo Youth Study. Prev. Med. 17:12-24, 1988.

40. Troiano, R. R., K. M. Flegal, R. J. Kuczmarski, S. M. Cambell, and C. L. Johnson. Overweight prevalence and trends for children and adolescents: the National Health and Nutrition Examination Surveys, 1963 to 1991. Arch. Pediatr. Adolesc. Med. 149:19851991, 1995.

41. Twisk, J. W. R., C. Boreham, G. Cran, J. M. Savage, J. J. Strain, and W. Van Mechelen. Clustering of biological risk factors for cardiovascular disease and the longitudinal relationship with lifestyle of an adolescent population: the Northern Ireland Young Hearts Project. J. Cardiovasc. Risk 6:355-362, 1999.

42. Twisk, J. W. R., H. C. G. Kemper, W. Van Mechelen, and G. B. Post. Tracking of risk factors for CHD over a 14 year period: A comparison between lifestyle and biological risk factors with data from the Amsterdam Growth and Health Study. Am. J. Epidemiol. 145:888-898, 1997.

43. Van Mechelen, W., H. Hlobil, and H. C. G. Kemper. Validation of two running tests as an estimate of maximal aerobic power in children. Eur. J. Appl. Physiol. 55:503-506, 1986.

44. Weiner, J. S., and J. A. Lourie (Eds.). Human Biology: A Guide to Field Methods, IBP Handbook No. 9. Oxford: Blackwell, 1968.

45. Whaley, M. H., J. B. Kampert, H. W. Kohl III, and S. N. Blair. Physical fitness and clustering of risk factors associated with the metabolic syndrome. Med. Sci. Sports Exerc. 31:287-293, 1999. 